Aletria, Belo Horizonte, v. 31, n. 1, p. 35-54, 2021

(c) (1)

\title{
Roberto Calasso e a edição como gênero literário
}

\section{Roberto Calasso and Publishing as a Literary Genre}

\author{
Kelvin Falcão Klein \\ Universidade Federal do Estado do Rio de Janeiro (UNIRIO). Rio de Janeiro, Rio de \\ Janeiro / Brasil \\ kelvin.klein@gmail.com \\ http://orcid.org/0000-0002-8997-1174
}

\begin{abstract}
Resumo: O objetivo do artigo é expor, contextualizar e analisar a proposição feita pelo escritor e editor italiano Roberto Calasso acerca da "edição como gênero literário", presente em um dos ensaios de seu livro A marca do editor. Para Calasso, a configuração da edição como gênero literário está na capacidade de absorver novidades e, ao mesmo tempo, permanecer fiel a certo padrão de excelência, fidelidade assegurada pelo editor. Disso decorre a ênfase dada por Calasso aos casos exemplares, dos quais se destacam Aldo Manúcio (1449-1515) e Kurt Wolff (1887-1963). A partir de noções como as de "livro único" e "bricolagem", resgatando autores como Claude Lévi-Strauss, Aby Warburg e Jorge Carrión, este artigo busca relacionar criticamente várias etapas da carreira de Calasso e da editora Adelphi, analisando as repercussões filosóficas, culturais e técnicas de suas reflexões sobre o trabalho da edição.
\end{abstract}

Palavras-chave: Roberto Calasso; Adelphi; Aldo Manúcio; Kurt Wolff; edição; bricolagem.

Abstract: The purpose of the article is to expose, contextualize and analyze the proposition made by the Italian writer and editor Roberto Calasso about "publishing as a literary genre", present in one of the essays in his book The editor's mark. For Calasso, the secret of publishing as a literary genre lies in the ability to absorb new elements and, at the same time, remain faithful to a certain standard of excellence, something that is guaranteed by the editor. It is for this reason that Calasso emphasizes exemplary cases, of which Aldo Manúcio (1449-1515) and Kurt Wolff (1887-1963) stand out. Starting 
from ideas such as "single book" and "bricolage", rereading authors such as Claude Lévi-Strauss, Aby Warburg and Jorge Carrión, this article seeks to critically relate several stages of Calasso's career at Adelphi, analyzing the philosophical, technical, and cultural aspects of his reflections on the work of the publishing.

Keywords: Roberto Calasso; Adelphi; Aldo Manúcio; Kurt Wolff; publishing; bricolage.

Em 17 de outubro de 2001, o escritor Roberto Calasso - diretor da editora italiana Adelphi - apresentou em Moscou, no Museu Estatal de Arquitetura Shchusev, a conferência intitulada "A edição como gênero literário" (CALASSO, 2020, p. 83-95). O texto está disponível em livro desde 2014, quando Calasso lançou o volume L'impronta dell'editore, traduzido no Brasil por Pedro Fonseca e lançado pela editora Âyiné em 2020 com o título A marca do editor. Trata-se de uma reunião de textos diversos de Calasso, todos dedicados ao trabalho editorial: "Os livros únicos", que abre o volume, é o mais longo, composto por três sessões de origens diversas (a primeira apareceu no jornal La Repubblica em dezembro de 2006, a segunda é inédita e a terceira é o texto de abertura da exposição "Religiões e mitologias: um itinerário no catálogo Adelphi", de dezembro de 1995); outros dois ensaios são seguidos por cinco perfis em homenagem a cinco editores (Giulio Einaudi, Luciano Foà, Roger Straus, Peter Suhrkamp e Vladimir Dimitrijević), o mais antigo escrito em 1975 (Suhrkamp), o mais recente em 2005 (Foà); o volume se encerra com três ensaios curtos, dos quais o último se destaca, "A folha solta de Aldo Manúcio", discurso de 2009 dedicado à rememoração do célebre editor e tipógrafo do Renascimento.

A ideia da "edição como gênero literário" é mais um esforço de Calasso visando a articulação de seus dois campos de atuação, como autor e editor, que há décadas dialogam e se retroalimentam. Já em 1962, aos 21 anos de idade, Calasso passa a atuar como editor, incorporado à equipe inicial da Adelphi pelos fundadores Luciano Foà e Roberto Olivetti. Em 1966, faz a tradução e uma longa introdução para $O$ conto do peregrino, de Santo Inácio; em 1969, faz o mesmo com Ecce homo, de Nietzsche; em 1972, com Ditos e contraditos, de Karl Kraus. Em 1974, publica seu primeiro livro, L'impuro folle, um ensaio narrativo sobre Daniel Paul Schreber e suas Memórias de um doente dos nervos, lançadas originalmente em 1903 e comentadas ao longo do século XX por 
uma série de pensadores, de Freud a Lacan, passando por Elias Canetti e Friedrich Kittler. A edição italiana das Memórias de Schreber foi lançada pela Adelphi, não por acaso, também em 1974 - e conta com um posfácio de Calasso, "Nota sobre os leitores de Schreber", que pode ser lido na coletânea Os 49 degraus (CALASSO, 1997, p. 83-107).

O livro de 1974 já apresenta tanto a erudição quanto a peculiar mescla de discursos e disciplinas (psicologia, mitologia, antropologia, história da arte e da literatura) que Calasso vai aprofundar a partir da década de 1980, quando inicia uma espécie de obra-mosaico ainda em curso, composta de vários títulos. Tudo começa em 1983, com a publicação de A ruína de Kasch, livro de difícil categorização, marcado pelo tom ensaístico e que tem como centro organizador a figura de Charles-Maurice de Talleyrand-Périgord (1754-1838); As núpcias de Cadmo e Harmonia, narrativa ensaística dedicada a uma recapitulação dos mitos gregos, sai em 1988 e se torna um best-seller, vencendo o Prêmio de Melhor Livro Estrangeiro na França em 1991; em 1996, Calasso lança $K a$, bastante semelhante ao anterior, mas dedicado ao contexto indiano e aos Vedas do hinduísmo; em 2002, surge $K$., sobre a obra de Franz Kafka (com ênfase nos manuscritos guardados na Bodleian Library de Oxford); O rosa Tiepolo, de 2006, segue o percurso monográfico e se debruça sobre a obra do pintor veneziano Giambattista Tiepolo; La Folie Baudelaire, de 2008, é dedicado a Charles Baudelaire; O Ardor, de 2010, retorna aos Vedas e à análise filológica do sânscrito; $O$ caçador celeste, de 2016, aborda a passagem da humanidade coletora para a caçadora; $O$ inominável atual, de 2017, é um estudo comparativo entre o fascismo da década de 1930 e o cenário atual do terrorismo midiatizado; e, por fim (até o momento), O livro de todos os livros, de 2019, traz um estudo sobre a Bíblia.

Portanto, é preciso ter em mente, quando se lê a conferência de Calasso sobre a "edição como gênero literário", que ela está em aberto diálogo com uma ampla e complexa obra. Além dos títulos citados, ligados à mencionada obra-mosaico em andamento, Calasso também publicou uma série de livros mais diretamente ligados ao ofício de editor. Cem cartas a um desconhecido, por exemplo, lançado em 2003, reúne cem orelhas escritas por Calasso para livros lançados pela Adelphi ao longo dos anos. A loucura que vem das ninfas, de 2005, também reúne ensaios, conferências e artigos de jornal, textos variados dedicados a autores como Kafka, Bruce Chatwin e Vladimir Nabokov (registrando, além disso, a primeira publicação em livro da conferência sobre a edição 
como gênero literário). Por fim, Como organizar uma biblioteca, lançado em 2020, reúne quatro artigos sobre questões diversas ao redor do livro, das revistas de divulgação às resenhas, passando pela apreciação de distintos pioneiros (Aby Warburg, Gabriel Naudé) e pela discussão sobre os diversos modos de se organizar bibliotecas e livrarias:

A melhor ordem, para os livros", escreve Calasso (2020a, p. 11, tradução nossa), "deve ser plural, ao menos tanto quanto a pessoa que os usa. Deve ser também sincrônica e diacrônica: geológica (para estratos sucessivos), histórica (por fases, caprichos), funcional (ligado ao uso cotidiano), maquinal (alfabética, linguística, temática). ${ }^{1}$

A conferência de 2001 começa com uma constatação de ordem econômica, desdobrada em uma perspectiva dupla: em primeiro lugar, Calasso (2020, p. 83-84) afirma que a editoria nem se compara à venda de "água mineral, computadores ou sacolas plásticas", muito mais rentáveis; em segundo lugar, a editoria muitas vezes "se mostrou uma via rápida e segura para dilapidar e dissipar patrimônios substanciosos", paradoxalmente mantendo ao longo do tempo uma dimensão de "prestígio". Ainda que essa aproximação entre prestígio e rentabilidade seja apenas um movimento de abertura no texto de Calasso, ela se tornou central no panorama editorial dos últimos anos, especialmente tendo em vista o modelo de negócio da Amazon, que precariza as condições de trabalho em escala global, ao mesmo tempo em que lucra com o acesso irrestrito aos dados pessoais dos usuários. Jorge Carrión (2020, p. 27-28), por exemplo, em seu livro Contra Amazon, escreve que "a Amazon se apropriou do prestígio dos livros" para construir "o maior hipermercado do mundo com uma grande cortina de fumaça em forma de biblioteca", defendendo "o acesso ilimitado à informação, à comunicação e aos bens de consumo", ao mesmo tempo em que faz "seus funcionários assinar

\footnotetext{
1 "Il miglior ordine, per i libri, non può che essere plurale, almeno altrettanto quanto la persona che usa quei libri. Non solo, ma deve essere al tempo stesso sincronico e diacronico: geologico (per strati successivi), storico (per fasi, incapricciamenti), funzionale (connesso all'uso quo ti dia no in un certo momento), macchinale (alfabetico, linguistico, tematico). È chiaro che la giustapposizione di questi criteri tende a creare un ordine a chiazze, molto vicino al caos. E questo può suscitare, a seconda dei momenti, sollievo o sconforto" (CALASSO, 2020a, p. 11).
} 
contratos de confidencialidade", construindo "um estado paralelo, transversal, global, com as próprias regras e leis, burocracia e hierarquia".

$\mathrm{O}$ editor italiano prossegue, afirmando que a editoria é uma arte, mas uma arte perigosa, justamente por conta de sua dependência do dinheiro. O perigo está na tentação de cercar bons livros de outros com qualidade duvidosa, na esperança de que a receita gerada pelos últimos permita a manutenção do trabalho junto aos primeiros: "O mercado - ou a relação com aquele desconhecido, obscuro ser que é chamado 'o público' - é a primeira provação do editor”, escreve Calasso, (2020, p. 93), "na acepção medieval do termo: uma prova de fogo que pode também fazer virar cinzas uma grande quantidade de dinheiro. Portanto, a edição poderia ser definida como um gênero literário híbrido, multimídia". O hibridismo da edição como gênero literário está em sua capacidade de absorver novidades e, ao mesmo tempo, permanecer fiel a certo padrão de excelência - uma fidelidade que deve ser assegurada pelo editor, pelo trabalho continuado de um indivíduo, e disso decorre a ênfase que Calasso frequentemente dá aos casos exemplares. Para resolver, até certo ponto, a tensão entre esses dois polos (novidade e excelência), Calasso recorre em sua conferência a dois exemplos, o pioneiro Aldo Manúcio (1449-1515), e o editor alemão Kurt Wolff (1887-1963).

A analogia inicial de Calasso é entre a imprensa e a fotografia: duas tecnologias inovadoras que foram levadas à excelência por trabalhadores de primeira hora, Manúcio para a imprensa, Nadar para a fotografia. "Manúcio foi o primeiro a imaginar uma editora em termos de forma", escreve Calasso (2020, p. 86), tanto a forma que coordena a sequência de obras a publicar quanto a forma material e direta do livro, sua condição de objeto, "a capa, o projeto gráfico, a diagramação, os tipos, o papel”. Além disso, o próprio Manúcio costumava escrever sob forma de cartas "aqueles breves textos introdutórios que são os precursores não apenas de todas as modernas introduções, prefácios e posfácios, mas também de todas as orelhas, dos textos de apresentação aos livreiros e da publicidade atual". Para Calasso, o percurso de Manúcio na exploração das potencialidades técnicas da imprensa também o leva a estabelecer a edição como gênero literário. $\mathrm{O}$ cuidado com a forma é o que permite reconhecer que um livro pertence a um conjunto de livros idealizado pelo mesmo indivíduo, que busca marcar (a impronta do editor) em cada exemplar uma visão de mundo e uma postura diante do ofício. Calasso extrapola para o trabalho de edição a noção de gênero, ou seja, segundo o Aurélio (FERREIRA, 
1986, p. 844), “qualquer agrupamento de indivíduos, objetos, ideias, que tenham caracteres comuns". O aspecto decisivo está nesses "caracteres comuns", compartilhados, que transformam os livros publicados por um editor em uma sequência reconhecível, elos de uma mesma corrente "ou fragmentos de um único livro composto de todos os livros publicados por esse editor", segundo Calasso (2020, p. 86).

Em vários momentos de A marca do editor - livro composto por textos de diferentes épocas, como salientado acima - Calasso retorna indiretamente a essa concepção do "gênero" ligado à edição e à criação de uma "forma" específica ligada ao trabalho editorial. Faz referência à "cultura Suhrkamp" (expressão cunhada por George Steiner, 1973, p. 253), por exemplo, "onde encontramos quase todo o melhor da cultura alemã crítica depois da guerra", e também ao "gosto Gallimard", a "Companhia das Î́ndias do papel impresso" que se sustenta sobre "uma capa branca com duas linhas vermelhas e uma preta" (CALASSO, 2020, p. 130-132). A Suhrkamp Verlag foi fundada em 1950 por Peter Suhrkamp, falecido em 1959 e sucedido por Siegfried Unseld no comando da editora (Unseld é um modelo para o livro do próprio Calasso, uma vez que lançou um trabalho muito semelhante em 1978, disponível no Brasil na tradução de Áurea Weissenberg e publicado com o título $O$ autor $e$ seu editor (UNSELD, 1986). A Gallimard, por sua vez, foi fundada em Paris, em 1911, por Gaston Gallimard, André Gide e Jean Schlumberger.

No caso de Manúcio, sua excepcionalidade decorre do fato de ter inaugurado, com alto grau de excelência, duas vertentes opostas do ofício da edição: de um lado o livro único, raro, delicado e enigmático (o Hypnerotomachia Poliphili, de 1499, escrito em uma língua imaginária, misto de italiano, latim e grego, e ricamente ilustrado); de outro, o livro barato, acessível e de fácil manuseio, o arquétipo do livro de bolso (uma edição das Tragédias, de Sófocles, lançada em 1502 e que usa pela primeira vez os caracteres gregos cursivos). Manúcio, portanto, foi capaz de atingir dois resultados opostos: por um lado, escreve Calasso (2020, p. 88),

criar um livro como Hypnerotomachia Poliphili que jamais teria igual, e é quase o arquétipo do livro único. Por outro, criar um livro completamente diferente, como o Sófocles, que, ao contrário, seria copiado milhões e milhões de vezes em todos os lugares, até hoje. 
Em seu estudo dedicado a Manúcio, Enric Satué (2004, p. 4243) fala da "sinergia sem dúvida impensável, não só em seu tempo mas ainda hoje" das atividades conjuntas de editor, tipógrafo e livreiro, destacando "o agrupamento de livros, pela primeira vez, numa única série ou coleção" e "o achado do formato de bolso" como inovações do editor veneziano. É possível mencionar ainda que a edição italiana mais recente do Hypnerotomachia Poliphili foi feita pela Adelphi, em 1998, e a edição brasileira, intitulada $A$ batalha de amor em sonho de Polifilo (tradução de segunda mão do espanhol), foi publicada em 2013 pela Imprensa Oficial do Estado de São Paulo em conjunto com a Oficina do Livro Rubens Borba de Moraes (COLONNA, 2013).

Depois de Manúcio, Calasso oferece o exemplo de Kurt Wolff, com a intenção de mostrar à sua audiência que traços do trabalho de edição do Renascimento permanecem válidos ainda hoje. Wolff, "jovem alemão, elegante, um pouco abastado", queria "publicar novos escritores de alta qualidade literária" e, por conta disso,

inventou para eles uma coleção de livros breves, com um formato inusitado, chamada "Der Jüngste Tag", "O dia do juízo", um título que hoje parece completamente apropriado para uma coleção de livros que foram publicados em grande parte durante a Primeira Guerra Mundial (CALASSO, 2020, p. 89).

A coleção de Wolff (que durou de 1913 a 1921) era composta por livros de cor preta, em sua maioria finos, com etiquetas de diferentes cores coladas na capa, lembrando cadernos escolares, nas quais se via título e autoria. Em 1915, a primeira edição de A metamorfose, de Franz Kafka, é publicada por Wolff na coleção. Em 1917, Wolff publica uma coletânea com textos de alguns jovens autores: Franz Blei, Albert Ehrenstein, Georg Heym, Franz Kafka, Else Lasker-Schüler, Carl Sternheim, Georg Trakl, Robert Walser. Segundo Calasso (2020, p. 90), são os

nomes dos escritores que, naquele ano, se encontraram reunidos sob o teto do mesmo jovem editor. E aqueles mesmos nomes, sem exceção, fazem parte da lista dos autores essenciais que um jovem hoje deve ler se quiser saber algo sobre a literatura alemã dos primeiros anos do século XX. 
Ao se arriscar na publicação (durante a guerra) de autores jovens e desconhecidos, Wolff contribuiu para a ampliação do campo literário no século XX.

As próprias memórias de Wolff, publicadas em 1965 (Autoren, Bücher, Abenteuer. Betrachtungen und Erinnerungen eines Verlegers, traduzido no Brasil como Memórias de um editor), indicam, contudo, que o olhar do editor não era infalível e que sua história é feita também dos deslizes cometidos. "Alguns episódios que parecem irrelevantes quando acontecem, depois, passados muitos anos, tornam-se aventuras memoráveis", escreve Wolff (2018, p. 71-73), relembrando uma carta que recebeu de James Joyce, datada de maio de 1920: "ao ler essas linhas, devo ter imaginado qualquer coisa do tipo: quem será esse professor excêntrico, que, em um alemão lamentável, me manda um livro inglês de Trieste e me propõe uma edição alemã?". Mesmo já tendo publicado Dublinenses e $O$ retrato do artista quando jovem (que pouco circularam), Joyce não conseguiu chamar a atenção de Wolff (Ulisses sairia dois anos depois, em Paris). "A aventura, nesse caso, é ter reencontrado essa carta, quarenta anos depois", escreve Wolff (2018, p. 74), "e o reconhecimento de um fato: se a editora Kurt Wolff tivesse publicado um livro anterior de Joyce, sem dúvida teria também publicado Ulisses, o livro em língua inglesa mais importante do nosso século". A "falta de visão" de Wolff com relação a Joyce talvez se explique por seu apego aos autores de língua alemã, algo que Calasso sinaliza diretamente (pode-se argumentar, além disso, que essa limitação é peça determinante para a definição da "forma" e do "estilo" de Wolff como editor e, portanto, de seu exercício da edição como gênero literário).

Para Calasso, Wolff e Manúcio foram editores que trabalharam a partir das mesmas diretrizes: o desejo de dar forma reconhecível a um conjunto de livros; a atenção permanente à boa apresentação gráfica e material de cada volume; a preocupação com o desenvolvimento de estratégias que permitissem vender os livros ao maior número possível de leitores. Além do desenvolvimento inovador de tipos, modos de encadernação e de utilização de materiais (a lombada plana, a substituição da madeira pelo cartão nas capas, o ouro aquecido para gravação), Manúcio organizou ao seu redor um grupo de trabalhadores altamente qualificados: Pietro Bembo foi responsável pela edição dos poemas de Petrarca, Erasmo traduziu Eurípides do grego para o latim, e, 
como se não bastasse, (...) Aldo inaugurou ainda com as Bucólicas, as Geórgicas e a Eneida de Virgílio a coleção de bolso mais antiga do mundo, inventando além disso um tipo novo, projetado especialmente para sua adaptação ao formato pequeno do livro (10 x $15 \mathrm{~cm}$ mais ou menos) (SATUÉ, 2004, p. 104).

Wolff, por sua vez, à frente da Kurt Wolff Verlag de 1913 a 1940, foi fundamental para a difusão do ramo literário do expressionismo alemão e para a consolidação (também no exterior) das obras de autores como Karl Kraus, Heinrich Mann, Rainer Maria Rilke e Boris Pasternak.

O que aproxima Manúcio de Wolff e, segundo Calasso, deve aproximar todos aqueles que trabalham com edição de livros, é uma concepção totalizadora e harmonizadora do ofício. "Sugiro modestamente considerar também a arte da edição como uma forma de bricolagem", escreve Calasso (2020, p. 91), depois de resgatar Claude Lévi-Strauss e sua ideia de "considerar uma das atividades fundamentais do gênero humano - ou seja, a elaboração de mitos — como uma forma particular de bricolagem", uma vez que "os mitos são constituídos de elementos já prontos, muitos dos quais derivados de outros mitos". Lévi-Strauss apresenta a noção de "bricolagem" no primeiro capítulo de seu livro de 1962, O pensamento selvagem, intitulado "A ciência do concreto". O bricoleur joga com os elementos de uma multiplicidade de discursos e disciplinas. "A regra de seu jogo", segundo Lévi-Strauss (1989, p. 33), "é sempre arranjar-se com os 'meios-limites', isto é, um conjunto sempre finito de utensílios e de materiais bastante heteróclitos", uma vez que a configuração estabelecida pelo trabalho da bricolagem não se pauta por um projeto prévio, "mas é o resultado contingente de todas as oportunidades que se apresentaram para renovar e enriquecer o estoque ou para mantê-lo com os resíduos de construções e destruições anteriores". É com isso em mente que Calasso (2020, p. 91-92) propõe à sua audiência imaginar uma editora "como um único texto formado não apenas pela somatória de todos os livros que ela publicou", mas também por "todos os seus outros elementos constitutivos, como as capas, os textos de orelha, a publicidade, a quantidade de exemplares impressos e vendidos ou as diferentes edições em que o mesmo texto foi apresentado".

Essa preocupação de Calasso, na conferência de 2001, com o esforço de "bricolagem" diante dos "elementos constitutivos" do livro encontrará ampliação em 2003, quando lança Cem cartas a um desconhecido e escreve uma introdução intitulada "A orelha das orelhas" 
(texto que hoje também faz parte da coletânea $A$ marca do editor). Mais uma vez ele retoma a ideia da edição como gênero literário, como um livro composto de vários livros encadeados, agora aproximando a experiência do editor daquela do leitor: "Mas não é verdade que todos os livros que nos deram um certo prazer formam em nossa mente uma criatura complexa, cujas articulações estão, porém, ligadas por uma invisível afinidade?" (CALASSO, 2020, p. 102). Ao ligar a edição à bricolagem, Calasso mostra que seu trabalho como editor é indissociável de seu trabalho como escritor e intelectual, uma vez que a exposição dos meandros da edição (os bastidores e seus aspectos técnicos, a escolha das ilustrações de capa, o tipo de papel e de divulgação) se configura potencialmente como a exposição do pensamento e da criação. "As orelhas que escrevi (até hoje, 1.089) registram tudo isso", escreve Calasso (2020, p. 103), marcando o espaço da orelha como uma "estreita jaula retórica", "tão severa como a que pode oferecer um soneto", que impõe a escolha de "poucas palavras eficazes", semelhante à situação de "quando se apresenta um amigo a um amigo". O esforço de Calasso corresponde a uma desnaturalização do trabalho da edição, mostrando que a materialidade dos livros é indissociável da imaterialidade do pensamento, da fantasia e da imaginação.

Se, segundo Ricardo Piglia (2004, p. 117), "o crítico é aquele que encontra sua vida no interior dos textos que lê" e que "escreve sua vida quando crê escrever suas leituras", é possível propor a analogia de que, para Calasso, o editor é aquele que escreve sua vida (sua visão de mundo, seu temperamento) quando crê editar livros alheios. Encerrando a conferência de 2001, Calasso (2020) evoca "os vastos domínios da Gallimard", nome "conhecido até nos confins mais remotos onde se estende a língua francesa", domínios que vão "das tenebrosas florestas e dos pântanos da Série Noire [...] aos planaltos da Pléiade"; ou ainda as "vastas propriedades da Insel Verlag, que dão a impressão de terem pertencido por muito tempo a um iluminado feudatário que no fim deixou suas posses aos mais devotos e fiéis intendentes", exemplos da edição pensada como "uma obra literária em si, pertencente a um gênero específico", que "ostenta seus clássicos modernos" e da qual "é possível conceber mapas muito detalhados".

O mapa detalhado da sua trajetória na Adelphi é iniciado por Calasso (2020) no longo ensaio que abre $A$ marca do editor, intitulado "Os livros únicos". Nesse texto, Calasso entra em detalhes acerca da 
bibliodiversidade no catálogo da Adelphi, de seu posicionamento na relação entre criação autoral, produção editorial, tradução e revisão, além de comentar suas próprias escolhas no que diz respeito às inter-relações entre edição, artes gráficas e design editorial. A ideia de "livro único" vem de Roberto Bazlen, um dos fundadores da Adelphi e uma espécie de padrinho para Calasso. O livro único é "aquele em que imediatamente se reconhece que aconteceu alguma coisa ao autor e essa alguma coisa terminou por se depositar em um escrito", aponta Calasso (2020, p. 1415), acrescentando que são "também livros que haviam corrido um grande risco de não chegarem a se tornar livros" e apontando, como ressalva, que essa indefinição da noção de Bazlen decorria de sua formação "nos anos de máxima aspiração de autossuficiência da pura palavra literária - os anos de Rilke, Hofmannsthal, George". Calasso (2020) dá como exemplo o livro escolhido em 1965 para inaugurar a Biblioteca Adelphi, a coleção mais icônica da editora: o romance $A$ outra parte, de Alfred Kubin (1877-1959), "único romance de um não romancista", "escrito durante um delírio que durou três meses", coincidindo "perfeitamente com algo que aconteceu, uma única vez, ao autor", uma vez que "não houve nada semelhante, na vida de Kubin, antes daquele momento; nada semelhante depois", um romance, em suma, atípico e insólito, parente da obra de Kafka e de Jakob von Gunten, de Robert Walser (CALASSO, 2020, p. 15).

A ideia da "edição como gênero literário", portanto, é decorrente da noção de "livro único", algo que Roberto Bazlen cultivava desde antes da fundação da Adelphi e com a qual Calasso entra em contato em 1962, quando se junta à editora. "Uma vez escolhido o nome da coleção [Biblioteca Adelphi], era preciso então criar sua aparência", continua Calasso (2020, p. 17-18), especificando algumas das escolhas visuais da editora: era preciso evitar o branco, pois "era o ponto forte da gráfica Einaudi, a melhor então em circulação - e não apenas na Itália", daí a necessidade de "diferenciar ao máximo", investindo "na cor e no papel fosco", "que nos acompanha desde então"; e, em "relação às cores", "aquelas que eram utilizadas na época na editoria italiana eram de certo modo poucas e grosseiras. Várias gamas de tonalidades intermediárias permaneciam inexploradas"; por fim, com relação às capas, era fundamental evitar "certas regras um tanto carolas observadas pelos seguidores da vulgata modernista". A longevidade do projeto gráfico da Biblioteca Adelphi (linhas retas na lombada e na capa, título e autoria 
centralizados, imagem de capa sempre emoldurada e destacada) mostra que a intenção de criar uma identidade visual singular, que separasse a editora das outras (como a Einaudi, citada por Calasso, ou a Gallimard, valorizada por sua economia de elementos), foi bem-sucedida.

As capas recebem um comentário pormenorizado. "Nunca encomendamos uma capa", escreve Calasso (2020, p. 22), pois "pensávamos que, no infinito repertório das imagens existentes - fossem elas quadros, fotografias ou desenhos -, poderíamos encontrar sempre, com um pouco de paciência e persistência, algo adequado para o livro que estávamos para publicar"; por isso, "por mais de trinta anos, [Luciano] Foà e eu selecionamos, aprovando e reprovando, centenas e centenas de imagens, formatos, cores de fundo". Bazlen, infelizmente, "não pôde participar desse jogo, pois o final da impressão do primeiro volume da Biblioteca coincidiu com o mês de sua morte: julho de 1965" (CALASSO, 2020, p. 23). Desde o início da editora Adelphi, Calasso sempre fez questão de comandar ao menos dois aspectos referentes à apresentação material do livro: as capas e as orelhas (resultando, inclusive, no livro que reúne 100 orelhas escritas por ele, em um conjunto de mais de mil, como comentado acima). Esses dois aspectos garantem o movimento dúplice de singularização da Adelphi e seu afastamento da "marca" (impronta) de outras editoras (embora esse "afastamento" seja também ambivalente, na medida em que a singularização dos livros da Adelphi ocorre sempre no contraste com outros projetos - sobretudo Einaudi, Gallimard e Suhrkamp). Além disso, as capas pensadas por Calasso se apresentam como esforços de estabelecimento de um diálogo com a tradição pictórica ("quadros, fotografias ou desenhos" já “existentes"), o mesmo acontecendo com as orelhas, textos nos quais Calasso não apenas apresenta o livro em questão, mas contribui para o mapeamento de suas filiações e seus ecos intertextuais.

"Com os anos e a prática, através dos erros e acertos, na busca de imagens adequadas para os livros da Biblioteca", escreve Calasso (2020, p. 27),

alguns critérios foram ficando mais precisos: antes de tudo evitamos, por princípio, os antigos mestres, os pintores excessivamente identificáveis e as imagens muito divulgadas, porque certo elemento surpresa - na própria imagem ou nas combinações - era um requisito essencial. 
A solicitação da tradição pictórica sofre aqui uma torção, na medida em que Calasso privilegia aquilo que não é "excessivamente identificável", com a intenção de promover uma sinergia entre a expectativa do conteúdo textual do livro e sua capa como "elemento surpresa". Com o efeito acumulado das décadas, as capas da Adelphi se tornam uma sorte de álbum ou de atlas, propondo uma linha narrativa alternativa no interior da tradição pictórica. Além disso, continua Calasso (2020, p. 27-28), "usamos sem cerimônia determinados artistas pouco conhecidos (como Spilliaert), ou nunca reconhecidos plenamente (como Vallotton), ou ainda não acolhidos na percepção geral (como Hammershøi)", construindo "uma espécie de clube de afins", relacionando artistas visuais a autores do catálogo: "George Tooker (para Kundera, Burroughs, Kunze, Nabokov, Sacks, Sciascia), Alex Colville (para Mutis, Simenon, Christina Stead, Pirsig), Oelze (para Benn, Sacks, Burroughs, Šalamov, C. S. Lewis), Meredith Frampton (para Nabokov, Muriel Spark, Ivy Compton-Burnett, Henry Green)". Diante das "várias centenas de imagens que figuraram nas capas da Biblioteca ao longo de quase cinquenta anos", escreve Calasso (2020, p. 28), "não deve ser difícil entrever um emaranhado de linhas que se sobrepõem às linhas canônicas da história da arte, contrapõem-nas e as perturbam".

É preciso mencionar que a obra e o pensamento do historiador da arte Aby Warburg (1866-1929) são pontos de referimento fundamentais para Calasso, não só no que diz respeito ao projeto das capas da Adelphi, mas também no que diz respeito ao seu trabalho como ensaísta e intelectual (uma presença que se encontra não só em Calasso, mas também na obra de nomes como Giorgio Agamben, Georges Didi-Huberman, Carlo Ginzburg e muitos outros). ${ }^{2}$ A inovação do pensamento de Warburg - que produziu monografias, ensaios e conferências, especialmente sobre a relação entre o Renascimento italiano e a Antiguidade pagã - está no projeto de seu Atlas Mnemosyne, um conjunto de painéis nos quais imagens de diferentes épocas e geografias são montadas lado a lado. Na década de 1920, Warburg

\footnotetext{
${ }^{2}$ Para além da consulta dos trabalhos dos autores mencionados (como, por exemplo, $A$ imagem sobrevivente: história da arte e tempo dos fantasmas segundo Aby Warburg, de Georges Didi-Huberman (2013), ou os ensaios de A potência do pensamento, de Giorgio Agamben (2017)), o artigo de Lenin Bicudo Bárbara, "Aby Warburg em português" (2016), oferece um completo panorama dos ensaios, livros e traduções publicados nos últimos anos em torno da obra de Warburg.
} 
(2009, p. 128) escreveu um texto introdutório ao Atlas Mnemosyne, afirmando que "a crise decisiva para cada artista" está no confronto "com o mundo das formas constituídas por valores expressivos já cunhados provenientes ou não do passado" e que "Mnemosyne deseja, com sua base de material visual, ser um inventário de pré-cunhagens documentáveis que propuseram a cada artista o problema da rejeição ou então da assimilação dessa massa compressora de impressões". É nessa tensão entre "crise" e "criação" (tendo como pano de fundo a tradição), exposta e tematizada por Warburg, que Calasso armou não só o conjunto de capas da Adelphi, mas muitos de seus livros de ensaios, com ênfase para $O$ rosa Tiepolo (2006) e La Folie Baudelaire (2008, não por acaso, livro vencedor do prêmio da Warburg Haus, de Hamburgo). Na resenha que escreve no Le Monde por conta da versão francesa do livro sobre Tiepolo, Marc Fumaroli qualifica Calasso como "o Aby Warburg italiano" (FUMAROLI, 2009).

Em entrevista para a The Paris Review, Calasso relembra sua temporada em Londres no início dos anos 1960 (concomitante ao início de seu trabalho na Adelphi), quando escrevia sua tese de doutorado (sobre Thomas Browne) e frequentava diariamente o Instituto Warburg (ZANGANEH, 2012). Em 1971, no primeiro número da Adelphiana (espécie de catálogo-revista lançado pela Adelphi, cujo segundo número saiu apenas em 2002), Calasso publica a sua tradução de um fragmento de Warburg sobre a relação entre Nietzsche e Jacob Burckhardt (extraído de uma caderneta de 1927), reimpressa na célebre edição de 1984, dedicada a Warburg, da revista aut aut (WARBURG, 1984, p. 46-49). Vinte anos depois, em junho de 1992, Calasso apresenta uma conferência no Collège de France, em Paris, intitulada "A loucura que vem das ninfas" (hoje disponível no livro de mesmo nome, La follia che viene dalle Ninfe, de 2005), na qual retoma e resume sua longa relação com a obra de Warburg, salientando a potencialidade de suas lições acerca de um uso crítico e criativo da tradição (CALASSO, 2005, p. 11-44). A reflexão warburguiana de Calasso é aprofundada em 2000, quando ele é convidado a dar as Weidenfeld Lectures em Oxford, hoje reunidas no livro A literatura e os deuses. "Os deuses se manifestam intermitentemente, de acordo com a expansão e o refluxo daquela que Aby Warburg chamou de 'onda mnêmica", escreve Calasso (2004, p. 25), especificando que a expressão "se encontra no início de um ensaio póstumo sobre Burckhardt e Nietzsche", aludindo "àqueles sucessivos choques de memória que 
atingem uma civilização em relação ao seu passado, neste caso àquela parte do passado ocidental que é habitada pelos deuses gregos".

Para Calasso, portanto, o procedimento editorial de escolha das capas dos livros é ancorado em um conjunto complexo de leituras, reflexões e posicionamentos intelectuais. A apresentação física e visual do livro repercute e responde à experiência de leitura do conteúdo por parte do editor, que busca, na confluência de exterior e interior, intensificar essa experiência com o artefato para o leitor. Desse modo, essa confluência é fundamental para a definição tanto do "livro único" quanto da edição como "gênero literário". No último movimento da segunda seção da conferência de 2001 (que será também o encerramento de minha análise aqui), Calasso observa o contraste entre a prática editorial singularizada da Adelphi e algumas das práticas editoriais recentes, como a "digitalização universal": "Estava escrevendo essas observações sobre as capas”, escreve Calasso (2020, p. 38),

quando o New York Times Magazine publicou um longo artigo de Kevin Kelly (definido como "um manifesto") com o título: "O que acontecerá com os livros?". O jornal descreve Kelly como "senior maverick" da revista Wired, portanto respeitável por definição.

O corte na argumentação de Calasso é deliberadamente abrupto, e com isso ele parece querer mostrar que o método Adelphi é minoritário e que sofre enorme pressão do mercado estadunidense, pautado pela homogeneização do "avanço" tecnológico. Kelly exalta o projeto de uma "biblioteca universal" capitaneado pelo Google, com o objetivo de digitalizar o conteúdo de grandes bibliotecas (de Harvard, Stanford, Oxford, da Universidade de Michigan e a New York Public Library), com a expectativa de ampliar o armazenamento para quadros, fotografias, filmes, composições musicais, transmissões de rádio e televisão e páginas web. "Trata-se, talvez, da forma mais avançada de perseguição já descrita", comenta Calasso (2020, p. 40): "a vida assediada por uma vida onde nada se perde e tudo é condenado a subsistir, sempre disponível, sufocante. Nesse quadro, os livros parecem uma remota província ou um reino de opereta".

Assim como o procedimento de escolha de capas da Adelphi corresponde a um complexo sistema de interações sociais e culturais (a relação entre inovação e tradição, o estreito diálogo entre história da literatura e da arte), a emergência do paradigma da "digitalização 
universal" corresponde, igualmente, a um sistema de vasta ramificação. Em livro de 2019, intitulado The Politics of Mass Digitization e publicado pela MIT Press, Nanna Bonde Thylstrup (2019, p. 38, tradução nossa) afirma que é preciso refletir sobre o processo histórico que levou ao "casamento entre uma empresa de tecnologia e as instituições de memória cultural", acrescentando que "o significado cultural, legal e político do Google Books, seja positivo ou negativo, não apenas enfatiza seu papel fundamental na formação de paisagens de conhecimento atuais", mas também

nos permite ver o Google Books como um prisma que reflete tendências políticas mais gerais com relação à globalização, à privatização e à digitalização, tais como modulações em infraestruturas institucionais, contextos legais e convenções políticas e estéticas. ${ }^{3}$

Tomando essa reconfiguração dos "contextos legais", Calasso (2020, p. 42) aponta, ironicamente, que "a digitalização universal se baseia [...] em uma certa benevolência em relação aos pobres e distantes estrangeiros". Em seu livro A nova idade das trevas, comentando de forma geral o ideal da "digitalização", James Bridle (2019, p. 57) afirma que "quanto mais ficamos obsessivos em computar o mundo, mais complexo e incognoscível ele parece", completando mais à frente: "a tecnologia é a condutora elementar da desigualdade em vários setores" (BRIDLE, 2019, p. 131).

A complexidade desse cenário é evocada por Calasso em sua crítica não só da postura de Kelly, mas de sua enfática e unilateral exaltação de toda a transformação de paradigma (e de uma espécie de contrato social ligado à circulação do livro). O ponto fundamental para Calasso (2020, p. 43) é que "a digitalização universal implica uma hostilidade para um modo do conhecimento", portanto, "não se trata de se preocupar com a sobrevivência do próprio livro, que já passou

\footnotetext{
3 "The cultural, legal, and political significance of Google Books, whether positive or negative, not only emphasizes its fundamental role in shaping current knowledge landscapes, it also allows us to see Google Books as a prism that reflects more general political tendencies toward globalization, privatization, and digitization, such as modulations in institutional infrastructures, legal landscapes, and aesthetic and political conventions" (THYLSTRUP, 2019, p. 38. Tradução nossa.).
} 
por poucas e boas e sobreviveu", e sim com a "destituição de um modo inteiro de conhecimento que é estreitamente ligado ao uso do livro". A aparente "democratização" vendida pelo paradigma de Kelly é, na visão de Calasso, um esforço de homogeneização da experiência de leitura (que envolve, como visto acima, uma complexa relação entre a materialidade do livro e a carga imaginativa despertada por seus elementos gráficos). "O texto - qualquer texto - é um pretexto", argumenta Calasso (2020, p. 46), e continua, citando as palavras de Kelly ao final:

Aquilo que conta é o link, a conexão. E nada melhor do que os números para fornecer sua dimensão. "Há cerca de 100 bilhões de páginas na rede, e cada página contém em média dez links. O resultado é 1 trilhão de conexões eletrificadas que atravessam a Rede".

A singularidade do livro é, diante disso, diluída dentro um fluxo acachapante de informações (um potencial "hipermercado" que em breve absorverá também "quadros, fotografias, filmes, composições musicais, transmissões de rádio e televisão e páginas web"). ${ }^{4}$

É nessa perspectiva que também pode ser pensada a ideia da edição como gênero literário: não apenas como um exercício isolado por parte do editor, mas como uma "partilha do sensível", usando a expressão no sentido dado por Jacques Rancière (2005, p. 16), na qual a performance do leitor é igualmente central para o processo de metamorfose da edição como gênero literário. O paradigma da digitalização dificulta essa partilha, instaurando o regime tautológico do fluxo e da rede, que Calasso reproduz em seu comentário: "aquilo que é (qualquer coisa que seja) foi substituído pela sociedade daqueles que vivem e falam, digitando e digitalizando dentro daquilo que é, qualquer coisa que digam" e, "quanto

${ }^{4} \mathrm{O}$ livro de Calasso pode ser lido com proveito em contraste com um livro anterior do historiador Robert Darnton, A questão dos livros: passado, presente e futuro, originalmente de 2009, no qual também se explora a relação entre as práticas editoriais contemporâneas e certos ecos históricos significativos (um dos casos exemplares de Darnton é o do editor Isaac-Pierre Rigaud, de Montpellier, responsável por Questions sur l'Encyclopédie, de Voltaire), além de comentar extensamente o projeto Google de digitalização: "Quando empresas como o Google olham para bibliotecas, não enxergam meros templos do saber. Veem ativos econômicos em potencial, aquilo que chamam de ‘conteúdo', prontos para serem explorados" (DARNTON, 2010, p. 29). 
ao mundo (...) é suprimido, tornado supérfluo em sua muda e refratária estranheza" (CALASSO, 2020, p. 48).

A trajetória de Calasso e suas reflexões sobre a edição postulam o livro como artefato híbrido, aberto ao mundo e a suas complexidades. Além disso, tanto o livro quanto o processo de edição surgem como pontos privilegiados de articulação entre a materialidade e a imaginação, entre o inovador e o tradicional - tensões que se atualizam sempre que o leitor reivindica uma posição crítica e ativa nesse processo.

\section{Referências}

AGAMBEN, Giorgio. A potência do pensamento: ensaios e conferências. Tradução de Antonio Guerreiro. Belo Horizonte: Autêntica Editora, 2017.

BRIDLE, James. A nova idade das trevas: a tecnologia e o fim do futuro. Tradução de Érico Assis. São Paulo: Todavia, 2019.

CALASSO, Roberto. A literatura e os deuses. Tradução de Jônatas Batista Neto. São Paulo: Companhia das Letras, 2004.

CALASSO, Roberto. A marca do editor. Tradução de Pedro Fonseca. Belo Horizonte; Veneza: Editora Âyiné, 2020.

CALASSO, Roberto. Come ordinare una biblioteca. Milão: Adelphi, 2020a.

CALASSO, Roberto. La follia che viene dalle Ninfe. Milão: Adelphi, 2005.

CALASSO, Roberto. Os 49 degraus. Tradução de Nilson Moulin. São Paulo: Companhia das Letras, 1997.

CARRIÓN, Jorge. Contra Amazon e outros ensaios sobre a humanidade dos livros. Tradução de Reginaldo Pujol Filho e Tadeu Breda. São Paulo: Elefante, 2020.

COLONNA, Francesco. Hypnerotomachia Poliphili. =A batalha de amor em sonho de Polifilo. Tradução da versão castelhana e da introdução de Pilar Pedraza por Cláudio Giordano. São Paulo: Oficina do Livro Rubens Borba de Moraes; Imprensa Oficial do Estado de São Paulo, 2013.

DARNTON, Robert. A questão dos livros: passado, presente e futuro. Tradução de Daniel Pellizzari. São Paulo: Companhia das Letras, 2010. 
DIDI-HUBERMAN, Georges. A imagem sobrevivente: história da arte e tempo dos fantasmas segundo Aby Warburg. Tradução de Vera Ribeiro. Rio de Janeiro: Contraponto, 2013.

FERREIRA, Aurélio Buarque de Holanda. Novo Dicionário Aurélio da Língua Portuguesa. 2. ed. 18. impressão. Rio de Janeiro: Nova Fronteira, 1986.

FUMAROLI, Marc. "Le Rose Tiepolo", de Roberto Calasso: dernier bal des dieux dans la Venise du XVIIIe siècle. Le Monde, [Paris], 22 out. 2009. Disponível em: https://www.lemonde.fr/livres/article/2009/10/22/ le-rose-tiepolo-de-roberto-calasso_1257209_3260.html. Acesso em: 10 ago. 2020.

LÉVI-STRAUSS, Claude. O pensamento selvagem. Tradução de Tânia Pellegrini. Campinas, SP: Papirus, 1989.

PIGLIA, Ricardo. Formas breves. Tradução de José Marcos Mariani de Macedo. São Paulo: Companhia das Letras, 2004.

RANCIÈRE, Jacques. A partilha do sensível: estética e política. Tradução de Mônica Costa Netto. São Paulo: EXO Experimental/Editora 34, 2005.

SATUÉ, Enric. Aldo Manuzio: editor, tipógrafo, livreiro: as pegadas de Aldo Manuzio. Tradução de Cláudio Giordano. Cotia: Ateliê Editorial, 2004.

STEINER, George. Adorno: love and cognition. Times Literary Supplement, Londres, s./n., p. 252-255, 9 mar. 1973.

THYLSTRUP, Nanna Bonde. The Politics of Mass Digitization. Cambridge, MA: MIT Press, 2019. DOI: https://doi.org/10.7551/ mitpress/11404.001.0001.

UNSELD, Siegfried. O autor e seu editor. Tradução de Áurea Weissenberg. Rio de Janeiro: Guanabara, 1986.

WARBURG, Aby. Burckhardt e Nietzsche. Revista Aut Aut, Firenze, n. 199-200, p. 46-49, jan./abr. 1984. Disponível em: https://autaut. ilsaggiatore.com/wp-content/uploads/2020/06/199-200.pdf. Acesso em: 11 ago. 2020. 
WARBURG, Aby. Mnemosyne. In: CAVALCANTI, Ana (org.). Arte \& Ensaios. n. 19. Rio de Janeiro, Programa de Pós-Graduação em Artes Visuais/Escola de Belas Artes, UFRJ, 2009, p. 125-131.

WOLFF, Kurt. Memórias de um editor. Tradução de Flavio Quintale. Belo Horizonte/Veneza: Editora Âyiné, 2018.

ZANGANEH, Lila Azam. Interview: Roberto Calasso, The Art of Fiction, n. 217. The Paris Review, Paris, n. 202, Outono 2012. Disponível em: https:/www.theparisreview.org/interviews/6168/the-art-of-fiction-no217-roberto-calasso. Acesso em 10 ago. 2020. 